\title{
DISTAL INTUSSUSCEPTION OF PROCESSUS VAGINALIS: A CAUSE OF ACUTE HYDROCELE
}

\author{
DAVID A. BLOOM, M.D. \\ JULIAN WAN, M.D. \\ ROBERT CILLEY, M.D.
}

From the Department of Surgery, Division of Urology,

University of Michigan, Ann Arbor, Michigan

\begin{abstract}
Acute obstruction of a patent processus vaginalis occurred in two boys, mimicking incarceration of an inguinal hernia. In fact, obstruction was caused by an intussusception of the processus vaginalis forming an intussuscipiens that occluded the hernia sac. This lesion, described previously in 1896 and in 1974, is one of the mechanisms by which an asymptomatic hernia or hydrocele becomes acutely symptomatic.
\end{abstract}

Acute presentation of an inguinal hernia or hydrocele is usually due to incarceration of omental, visceral, or genital structures. Testicular torsion, epididymitis, inflammation of the spermatic cord, infected hydrocele, and malignancy may mimic an incarcerated hernia. Intraperitoneal disorders such as appendicitis, abscess, hemorrhage, and metastatic cancer can track down into the scrotum via a patent peritoneal processus vaginalis. ${ }^{1-9}$ Acute obstruction of a patent processus vaginalis by the processus itself is an additional cause of acute hydrocele.

\section{CASE REPORTS}

\section{CASE 1}

In a one-year-old boy with a known but asymptomatic hydrocele an acute scrotal enlargement developed, with erythema and pain. The scrotal mass transilluminated but could not be reduced and was explored surgically through an inguinal incision. A large hernia sac contained clear fluid. The cord and sac were traced distally to a scrotal hydrocele which was delivered into the inguinal field. The hernia sac was dissected from adjacent cord structures, followed proximally to the internal inguinal ring, ligated, and divided. The scrotal hydrocele did not decompress and a probe would not pass through the distal portion of the hernia sac into the tense hydrocele. The parietal portion of tunica vaginalis was opened to inspect the testis and paratesticular structures which

Submitted: January 4, 1993, accepted: March 1, 1993 were all normal. No appendages were present. A necrotic mass was present where the distal portion of hernia sac abutted the separate hydrocele (Fig. 1). The mass was the remnant of a portion of distal processus vaginalis which intussuscepted into the cephalad portion of its adjacent hydrocele: that is, the previous communicating hydrocele became acutely obstructed by the intussuscipiens. The strangulated intussuscipiens and excess hydrocele sac were excised. The gonad was replaced in the scrotum, and the inguinal field was closed. Histopathologic examination of the necrotic lesion revealed compressed mesothelial elements with organizing hematoma and granulation tissue. On follow-up examination at one year, the child was well with normal testes and no further evidence of hydrocele or hernia.

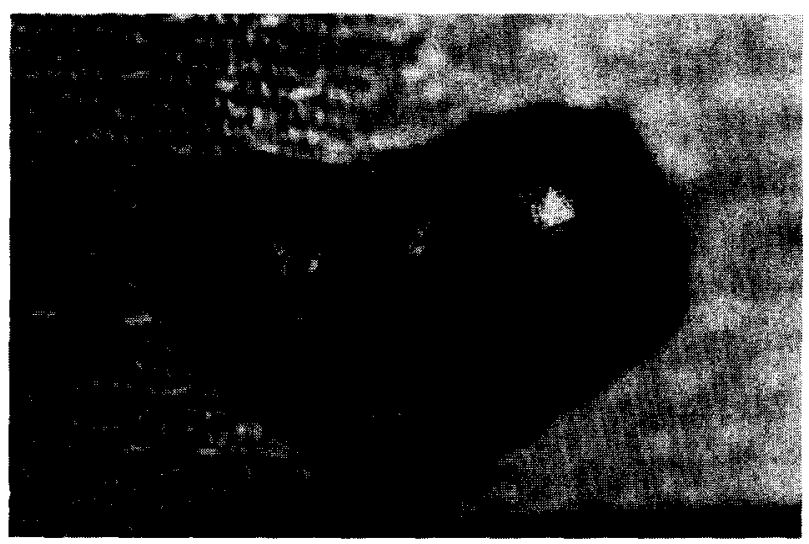

FIGURE 1. Obstructing intussuscipiens in hernia sac of one-year-old boy. 

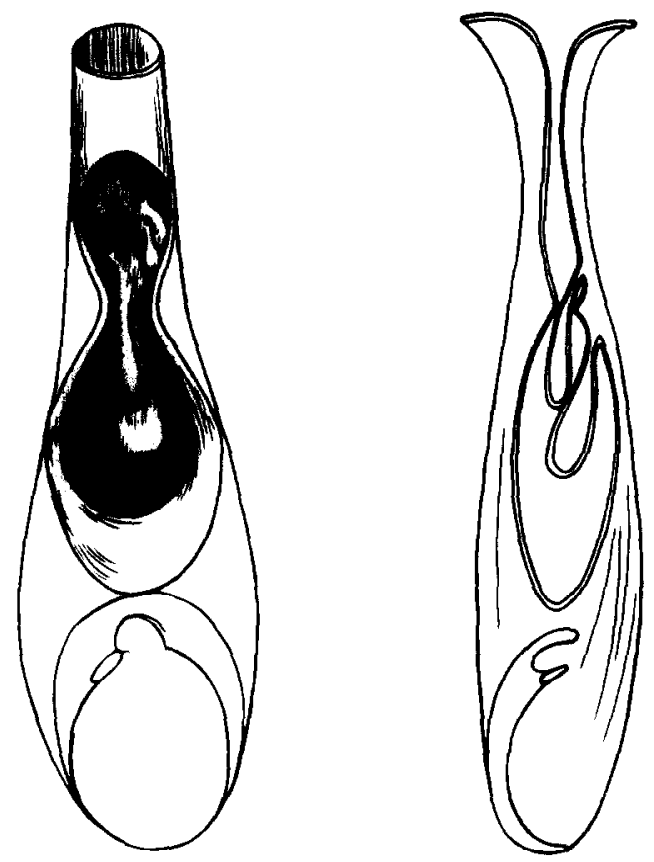

FIGURE 2. "Hernial sac laid open to show the pedunculated bodies" (redrawn from original, Lockwood, $1896^{10}$.

\section{CASE 2}

A twenty-one-month-old boy with cerebral palsy and a ventriculoperitoneal shunt had an asymptomatic left hydrocele which occasionally varied in size. He came to the emergency department one evening with an acutely painful left inguinal mass and scrotal erythema. The mass transilluminated poorly and could not be reduced. On abdominal $\mathrm{x}$-ray film, the shunt was well away from the inguinal canal.

At inguinal exploration a thick-walled hernia contained a pedunculated body that obstructed the lumen just proximal to the scrotal inlet. The lesion originated from the thickened hernia sac at the lateral wall in the distal half of the inguinal canal. The hernia sac was dissected free from other cord structures, mobilized to internal ring, ligated, and divided. Distal sac including the pedunculated nodule was excised. The testis and epididymis were normal without identifiable appendages. Histologic examination of the nodule revealed edematous mesothelial surfaces and granulation tissue in a rolled configuration. On follow-up at one year, he was well with normal testes and without recurrence of hydrocele or hernia.

\section{COMMENT}

Familiar findings in the inguinal canal include gonad of the appropriate sex, isolated cord hydrocele, fallopian tube, omentum, lipoma, hemato-

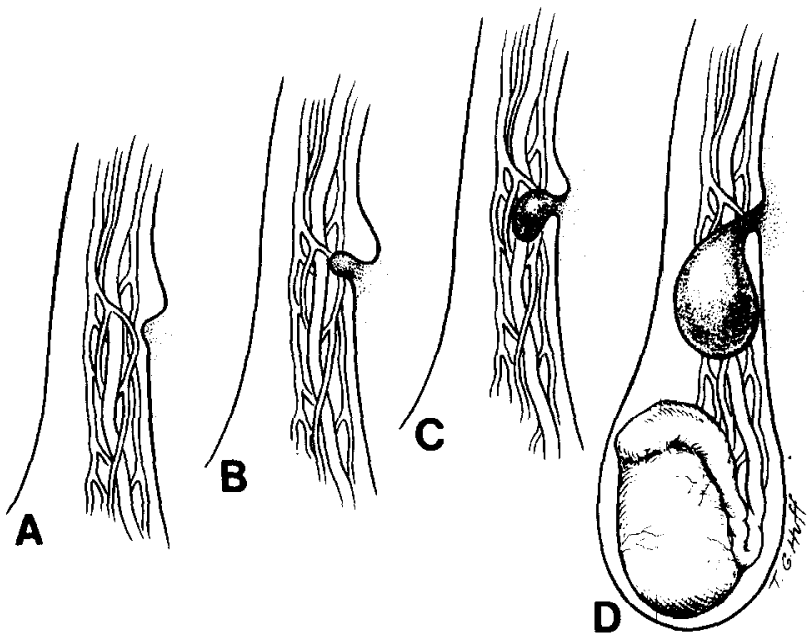

FIGURE 3. Hypothesis of formation of polyp and intussuscipiens within patent processus vaginalis.

cele, and intestine. A surgeon, however, must be prepared for the unexpected, because a hernia sac will occasionally harbor a surprise. Lockwood in $1896,{ }^{10}$ described pedunculated cysts within the hernia sac of an eighteen-year-old male. The illustrations in that report reveal partial distal intussusception of the patent processus vaginalis (Fig. 2). In 1974, Esho, Vitko, and Cass ${ }^{11}$ described protrusion and torsion of an inguinal hernia sac in a ten-year-old boy with anatomy nearly identical to the first case described herein.

In children with asymptomatic hernias or hydroceles, acute painful scrotal enlargements occasionally develop that mimic incarcerated hernias. In these instances the communication between the inguinal portion of the hernia sac and the scrotal hydrocele is generally very small, if demonstrable at all, and acute presentation most likely occurs when the marginal communication to the hydrocele becomes occluded. Lockwood's patient, the acute hydrocele of Esho et al., ${ }^{11}$ and the 2 cases described herein may be variants of the same problem wherein intra-abdominal pressure transmitted through a patent processus vaginalis causes inflammation, polyp formation, or intussusception at the inguinal-scrotal junction. The formation of a processus vaginalis polyp and obstructing intussuscipiens is hypothesized in Figure 3. Squire and Gough ${ }^{12}$ suggest a similar pathogenesis for abdominal scrotal hydrocele. Although acute hydrocele is a well-recognized phenomenon, the causes for this have not been widely documented. Spontaneous distal occlusion of a patent processus vaginalis because of inflammation, polyp formation, or intussusception of the processus itself is one such causal mechanism. 


\section{David A. Bloom, M.D \\ University of Michigan \\ Ann Arbor, Michigan 48109}

\section{REFERENCES}

1. Creese PG: The first appendectomy. Surg Gynecol Obstet 97: 643-652, 1953.

2. Alvear DT, and Rayfield MM: Acute appendicitis presenting as a scrotal mass. J Pediatr Surg 11: 91-92, 1976.

3. Skoog SJ, and Belman AB: The communicating hematocele: an unusual presentation of blunt splenic trauma. J Urol 136: 1092-1093, 1986.

4. Putnam MH: Neonatal adrenal hemorrhage presenting as a right scrotal mass (Letter). JAMA 261: 2958, 1989.

5. Mininberg DT, and Dattwyler B: Ectopic adrenal tumor presenting as torsion of spermatic cord in a newborn infant. J Urol 109: 1037-1038, 1973.

6. Velasco AL, Ophoven J, Priest JR, and Brennom WS:
Paratesticular malignant mesothelioma associated with abdominoscrotal hydrocele. J Pediatr Surg 11: 1065-1067, 1988.

7. Lewis LG, Goodwin WE, and Randall WS: Carcinoma of the spermatic cord and epididymis extension from primary carcinoma of the stomach. J Urol 51: 75-80, 1944.

8. Coolsaet B, and Weinberg R: Thrombosis of the spermatic vein in children. J Urol 124: 290-291, 1980.

9. Orlowski JP, Levin HS, and Dyment PG: Intrascrotal Wilms tumor developing in a heterotype renal analage of probable mesonephric origin. J Pediatr Surg 15: 679-682, 1980.

10. Lockwood $\mathrm{CB}$ : Pedunculated cysts within a hernial sac. Trans Path Soc London 47: 61-64, 1896.

11. Esho JO, Vitko RJ, and Cass AS: Protrusion and torsion of an inguinal hernia sac inside a hydrocele of the scrotum. J Pediatr Surg 9: 423, 1974.

12. Squire R, and Gough DCS: Abdominoscrotal hydrocele in infancy. $\mathrm{Br} \mathrm{J}$ Urol 61: 347-349, 1988. 